\title{
TRES CARTAS INEDITAS SOBRE LA PROPUESTA DE UN FRENTE ELECTORAL *
}

\begin{abstract}
A1 romperse, en 1933, la histórica coalición republicano-socialista, no dejó de observar Azaña que la necesaria recuperación o rescate de la República exigía un nuevo acuerdo con el PSOE y una reducción de las distancias entre los partidos republicanos. A ambas tareas dedicó alguna atención durante 1934 con resultado diverso: si entre los republicanos se consigue un avance sustancial en el camino de una «inteligencia» programática, los socialistas opusieron una negativa rotunda a las llamadas y sugerencias de Azaña, con el pretexto de que la República estaba moribunda y que la única perspectiva posible era asistir a su entierro.

Creyeron, sin embargo, los socialistas que la República sería tan fácil de enterrar como lo había sido la Monarquía y con los mismos medios: una huelga general y algunos disparos, a ser posible al aire. Así se llegó a octubre de ese año y así fueron a parar a la cárcel algunos de los dirigentes que durante 1934 se habían negado a charlat con los republicanos. Azaña, que empieza a hablar ahora en nombre de todos éstos, reanuda otra vez la comunicación con los socialistas por donde le resulta más fácil, por Prieto, que está en Francia, pero que cuenta aquí con un fiel miembro de la comisión ejecutiva, Vidarte. De este Vidarte, aunque con aprobación de Largo Caballero, sale un manifiesto a las agrupaciones en el que, básicamente, se pide que nadie tome iniciativa alguna que pueda obstaculizar un futuro acuerdo electoral con los republicanos, sobre cuya oportunidad se abre una votación entre los afiliados al partido.

Si a estas iniciativas se añade el hecho evidente de que la fracción de izquierda del PSOE se quedó sin política tras el descalabro de octubre y puso en barbecho sus veleidades de alianza exclusivamente obrera, puede explicarse sin más la rápida respuesta que la ejecutiva del partido da a la propuesta de pacto electoral que recibe de Azaña. Y será preciso insistir en que se trata de toda la ejecutiva, porque aún hoy suenan voces que presentan a Largo Caballero-y por tanto, a la dirección de la UGT - indeciso en su respuesta y sólo animado a darla positivamente pór influjo comunista. Insistir hoy en que la izquierda del PSOE fue a ese pacto empujada por un enviado de la Internacional Comunista - Jacques Duclos- no

* Estas cartas —originales en el caso de Azaña, copias en el de De Francisco- han regresado a España entre los papeles devueltos al PSOE por las autoridades soviéticas y se pueden consultar en el archivo histórico de la Fundación «Pablo Iglesias», a cuyos bibliotecarios quiero agradecer las facilidades de que siempre rodean al trabajo del investigador.
\end{abstract}


es más que obcecación en uno de los muchos tópicos que envuelven la historia política de la República. Estas cartas despejan las dudas que aún podían quedar: Largo Caballero acepta la propuesta un día después de recibirla y algunas semanas antes de sus entrevistas con Duclos.

La correspondencia aclara también la posición de Azaña ante la ampliación del pacto. Sabido es que Azaña no quería ir a parte alguna con los comunistas: «¿Adónde podemos ir nosotros, y ustedes, con los comunistas?», había preguntado a Prieto. Acepta ahora, sin embargo, su entrada en el acuerdo aunque inmediatamente pondrá una condición: los comunistas, y otros que pudieran sumarse, no participarán en las conversaciones, sino que delegarán su representación en el partido socialista. Los esfuerzos de Largo Caballero para sentarlos a la misma mesa tropezaron con una negativa inamovible. El pacto o frente electoral de que aquí se habla se cocerá después, en su concreción práctica, entre socialistas y republicanos. Los demás se limitarán a estampar su firma al pie del documento final.

Una palabra sobre el tono de las cartas, pues si en el de Azaña no hay novedades dignas de interés - ni siquiera en esa resignada insistencia en cosas evidentes para él desde mucho tiempo antes o en su insinuado escepticismo ante la posibilidad de obtener una respuesta inequivoca - sí podría sorprender, por el contrario, el tono claramente satisfecho y aun ceremoniosamente retórico de los socialistas. No hay, sin embargo, para asombrarse si se tiene en cuenta que la estimación popular de Azaña había subido como la espuma tras sus discursos «en campo abierto», cuyos ecos, que el propio Azaña se cuida de evocar, perduraban aún en el recuerdo de todos.

$\mathrm{Y}$ decir, finalmente, que a la reunión de la comisión ejecutiva del PSOE asisten Caballero, De Francisco, Wenceslao Carrillo, Pascual Tomás y Vidarte, o sea, la flor del ala radical del socialismo, que es al tiempo la nata de la dirección del ugetismo. Ninguna sorpresa, pues, si en la primera reunión que celebre el comité nacional de la UGT -11 de diciembre- la alianza electoral con los republicanos se apruebe también sin discusión alguna por el poderoso sindicato de los socialistas.

\section{SANTOS Juliá}

\section{EL DIPUTADO A CORTES POR BILBAO}

14 de noviembre de 1935

\section{Sr. D. Enrique de Francisco}

Mi distinguido amigo: Todo bace suponer que la presente situación política y parlamentaria toca a su término, el cual lleva consigo la necesaria consulta al sufragio universal. Es, por otra parte, innegable que la opinión pública, casi unánime, reclama y espera una coalición electoral de los partidos de izquierda. El que yo represento ba explicado repetidamente su posición en diversos actos públicos y de un modo especial en el celebrado en Madrid el 20 de octubre último. Estoy autorizado para decirle a usted que los partidos de Unión Republicana y Nacional Republicano, estiman igualmente necesaria la coalición. Aunque la iniciativa para entablar conversaciones dirigidas a lograrlo, no nos está asignada de un modo especial, 
escribo a usted, con la aquiescencia expresa de los otros partidos, para someter a su consideración la conveniencia de que la Comisión Ejecutiva del Partido Socialista, en su próxima reunión, examine el asunto y nos baga conocer, a ser posible, sus puntos de vista sobre la coalición electoral, de cuyo contenido programático bablariamos ulteriormente.

Con el ruego de que ponga esta carta en conocimiento de dicba Comisión Ejecutiva, me es grato reiterarme su muy afmo. amigo y s. s.

Manuel Azaña

16 de noviembre de 1935

Sr. D. Manuel Azaña

Presente

Muy distinguido amigo:

La Comisión Ejecutiva del Partido Socialista en su reunión de esta fecha, ba conocido la carta que por mediación del secretario que suscribe le dirige, con la aquiescencia expresa de los partidos republicanos que en usted vinculan bonrosamente su representación, con objeto de conocer nuestros puntos de vista sobre una coalición electoral.

Tenemos la satisfacción de comunicar a usted, y por su mediación a los partidos republicanos con cuya aquiescencia cuenta, que esta Comisión Ejecutiva, atenta a las realidades presentes $y$, por ello, conocedora de las aspiraciones de la opinión pública cuyo juicio puede interesarnos preferentemente, considera de gran conveniencia una coalición electoral con los partidos republicanos de izquierda, no implicados en las responsabilidades contraidas a partir del 4 de octubre de 1934 por los que usufructuaron o particparon en los gobiernos que, de la expresada fecha acá, se ban venido sucediendo.

Como consecuencia de esta declaración, gustosamente acepta la iniciación de conversaciones de las que pueda surgir un contenido programático sobre el que la expresada coalición pueda establecerse; pero, al propio tiempo, un deber de lealtad nos obliga a expresarles que, a nuestra vez, apreciamos como deber moral ineludible procurar que queden implicados en esta coalición otros organismos de carácter político o sindical obreros con los que, a tales efectos, babremos de establecer relación, por si este propósito nuestro pudiera merecer por parte de ustedes alguna objeción.

Al tener la satisfacción de trasladar a usted el criterio de esta Comisión Ejecutiva en relación con su consulta, me reitero como su buen amigo y s. s. q. e. s. $m$.

El Secretario, E. DE Francisco 


\title{
EL DIPUTADO A CORTES POR BILBAO
}

Madrid, 21 de noviembre de 1935

\section{Sr. D. Enrique de Francisco}

\section{Presente}

Mi distinguido amigo: He recibido su carta del 16 del corriente, en la que me transmite el acuerdo de la Comisión Ejecutiva del Partido Socialista relativo a la coalición electoral con los partidos republicanos, en cuyo nombre escribi a usted anteriormente, y nos sirve de satisfacción que ustedes, como nosotros, consideren conveniente, según lo aprecia la opinión pública, preparar esta coalición en vista de una probable convocatoria de elecciones de Diputados a Cortes.

Hallándose ustedes dispuestos a iniciar conversacions con ese propósito para trazar el contenido programático sobre que puede establecerse dicba coalición, le agradeceré que me indique cuándo y con qué personas podemos iniciar esos trabajos para los que también designaremos nosotros los delegados que bagan falta.

Con este motivo, me es grato reiterarme de usted atto. y s. s. q. e. s. m.

Manuel Azaña

22 de noviembre de 1935

Sr. D. Manuel Azaña

Presente

Muy distinguido amigo:

Recibo su atta. de fecha 21 del corriente de la que be de dar conocimiento a la Comisión Ejecutiva en su próxima reunión.

En nuestra carta del 16, daba a conocer a usted un extremo que para nosotros tiene importancia y que lo ofrecíamos a su conocimiento por si se considerasen en el caso de bacer alguna objeción, a saber, el de las relaciones que babríamos de entablar con otras entidades de carácter obrero a quienes pudiese alcanzar la inteligencia electoral.

Con propósito de evitar que su silencio sobre el particular pueda ser objeto de una nueva consulta y, por esto, causa de dilación de las negociaciones que bubieran de entablarse, le ruego me indique el juicio de ustedes sobre el extremo indicado para dárselo a conocer a esta Ejecutiva en la reunión que bemos de celebrar.

Para que tengan un conocimiento completo de las entidades con las que se ban iniciado ya las relaciones, consigno su relación nominal:

Partido Comunista Español, Federación de Juventudes Socialistas, Unión General de Trabajadores, Confederación General del Trabajo Unitaria.

En espera de sus gratas noticias me reitero de usted atto. amigo $y$ s. s. q. e. s. $m$.

\author{
El Secretario, \\ E. DE FRANCISCO
}




\section{EL DIPUTADO A CORTES \\ POR BILBAO}

Madrid, 30 de noviembre de 1935

Sr. D. Enrique de Francisco

Presente

Mi distinguido amigo: Recibí su carta en la que interesaba una aclaración respecto del extremo que me sometía usted en la anterior en cuanto a la actuación del frente electoral con otros grupos y organizaciones obreras, distintas del Partido Socialista. El no haber formulado ninguna observación en ese particular en mi carta anterior era signo de que no tenemos nada que oponer al caso, y precisamente en las conversaciones que se entablen para realizar la coalición podremos examinar las modalidades de esa actuación con el frente, en cuanto afecta a los republicanos, sin que opongamos ninguna objeción de principio a lo que usted me anunciaba.

Con este motivo, me reitero suyo afmo. amigo y s. s. q. e. s. m.

Manuel Azaña

5 de diciembre de 1935

Sr. D. Manuel Azaña

Presente

Muy distinguido amigo:

Acuso recibo de su grata fecha 30 del cpdo, que be dado a conocer a la Comisión Ejecutiva.

Dentro de breves días ba de reunirse nuestro Comité Nacional, y tendré el gusto de darle a conocer los acuerdos que adopte acerca del propósito de concertar la alianza electoral a que nos venimos refiriendo.

Entre tanto, me reitero muy suyo afmo. amigo y s. s. q. e. s. $m$.

El Secretario, E. DE Francisco 